\title{
THE EFFECTS OF IT-BASED TRAINING ON EMPLOYEES UPTAKE OF NEW TECHNOLOGIES IN THE WORK-PLACE
}

\author{
Lena Mae Wilkinson and Margaret Cox \\ Kings College London, UK
}

\begin{abstract}
This paper reports on Phase 1 of a project that investigates the personal and institutional factors influencing the effectiveness of information technology based training on the uptake and integration of IT in the work-place. The results show that personal factors such as attitudes towards IT and confidence in using it affect the trainees' abilities and willingness to use it in the work place. Institutional factors, such as the organization and delivery method of the training, the understanding of the trainee's needs and the design of the training programmes have been shown to limit the effectiveness of the training. The personal factors in the model are based on the Theory of Planned Behaviour, and the institutional factors have been identified from previous empirical evidence. Both have been adjusted to accommodate the results of Phase 1 .
\end{abstract}

Key words: IT-based training, training models, needs assessment, research, evaluation.

\section{INTRODUCTION}

During the past three decades, Information Technology has pervaded all levels of private and public sector organizations (Harrison, Mykytyn, \& Riemenschneider, 1997, Leidner \& Jarvenpaa, 1995, Wishart \& Blease, 1999). According to Roberts and Henderson (2000), by the year 1999 the penetration of IT in the workplace in the United States was approaching a ratio of one computer per person. However, although organizations spend approximately $\$ 20$ billion dollars each year on computer-related training, only $10 \%$ of training leads to a change in employees' work practices (Venkatesh \& Speier, 2000). Previous research provides evidence of employees developing a positive attitude towards IT (Nordenbo, 1990), 
being confident and liking working with computers (Roberts \& Henderson, 2000), and preferring a highly interactive and motivating computer training program (Leidner \& Jarvenpaa, 1995, Kettanurak, Ramamurthy, \& Haseman, 2001). Agarwal, Prasad, and Zanino (1996) found that users perceptions are good predictors of attitudes towards the use of IT, and individual differences contribute to training experiences and perceptions. However, according to Torkzadeh and Van Dyke (2002) and Chou (2001), more substantial research still needs to be conducted to measure the effects of individual and organizational factors on the effectiveness of IT-based training (IT-BT). This paper reports on Phase 1 of a research project that is investigating the personal and institutional factors which might contribute to the effectiveness of IT-BT and the integration of IT in the work-place.

\section{APPROACHES TO IT-BASED TRAINING}

For the purpose of this research, we have identified three types of IT-BT approaches; IT Specific, Applied, and Embedded. In the case of IT-BT (ITspecific) being studied in this research project, the trainees are learning how to operate a computer and also a particular IT package such as wordprocessing to use in the work-place. Applied IT-based means the use of an IT-based learning environment to teach particular skills and processes which may have no connection with using IT in the work-place (e.g. a role playing simulation to teach employees safety procedures). Embedded IT-based involves using bespoke packages to teach specific skills which may also be related to the software interface itself (e.g. training pilots to fly an aircraft using flight simulators).

\section{NEEDS ASSESSMENT}

In many of the previous investigations into the effects of IT-based training, there has been limited research into the ways in which organizations have assessed the training needs of their employees and how this assessment has thereby affected their training programmes (Salas \& Cannon-Bowers, 2001). According to Arnold et al. (1995, p.309), 'organizational analysis is important because it links trainees' training activities and organizational aims and objectives together'. An effective needs assessment programme involves not only identifying training needs but other procedures which may make the organization function more efficiently, such as redesigning the job, changing the equipment, improving 
recruitment and selection procedures, or providing job aids (Rossett \& Gautier-Downes, 1991).

Whatever the method of training being used (e.g. lecturing, workshops, on-line learning) research has shown that it is important when planning training that the organization identify the trainees' and organizational needs (e.g. Goldstein \& Ford, 2002). This can be done by examining plans and statements of policy and procedures, and by discussions with management, senior personnel, and employees in the organization. Venkatesh and Speier (2000) showed that there are still many limitations to the effectiveness of different IT-BT programmes.

The need for the use of theories which should underpin the design and evaluation of IT-BT was demonstrated by the research teams who were analysing the role functions of trainers for the TDLB (Training and Development Lead Body) Standards of Competence (Rae, 1995). The researchers reported that few effective approaches were observed. Also, there have been very few investigations reported in the literature, of the trainees' achievement of the learning objectives, their longer-term retention of knowledge, and their change in working practices. Specifically, there is little research evidence about the integrated relationship between the institutional and personal factors of IT-based training and the subsequent work practices of the employees.

\section{AIMS AND PHASES OF THE STUDY}

In order to study the effectiveness of IT-BT, our research involves investigating the personal factors relating to the trainees' experiences and changes in work practices, and the institutional factors relating to the organizational and management practices.

In Phase 1 of this study we conducted an extensive review of the IT-BT literature and investigated the context of the institution (involving 8 trainers and 185 employees), how the training was organized, the processes and methods used and the trainees' perceptions of the training. Phase 2 was to find out what external factors made a major contribution to the trainees' experiences and uptake of IT, the trainers' and trainees' attitudes and perceptions of the training and how it should be delivered. Phase 3 will collect more in-depth information about the trainees' change in attitude towards IT and training, whether they are continuing to use the same IT applications in their jobs, and how the uptake has affected the organization's training policies and procedures. 


\section{METHODOLOGY}

This paper focuses on Phase 1, which used a survey methodology, complimented by individual interviews and observations. This was based on the approach used by Wynekoop (1992) who studied the implementation of computer-aided software engineering (CASE) tools in organizations combining qualitative and quantitative methods. The instruments for the survey included a 37-item trainee questionnaire to measure the trainee's perceived training needs, knowledge about IT and their perceptions of the training courses which they had attended. This same questionnaire was also administered to three trainees immediately after a training course on "Welcome to Word for Windows" to measure their immediate perceptions of this specific course and what they had learnt. A 26-item trainer questionnaire was used to assess how the training was structured, the organizational policies and procedures concerning the training, and the identified training needs of the employees. An interview with the Director of the Department of Information Technology Training, document collection and structured observations of one training session were used to gather more in-depth information about the training courses and the training experiences.

\section{RESULTS OF PHASE 1}

Selected results for Phase 1 are presented in the following sections.

\subsection{Phase 1: Literature Review}

Previous IT-BT studies were reviewed to provide the basis for the development of a conceptual framework using psychological attitude theories (Shifter \& Ajzen, 1985), and organizational factors identified from the review. The literature revealed personal factors which had an impact on training effectiveness; for example, attitude towards IT, ease of use, and perceived behavioural control (Roberts \& Henderson, 2000), and organizational factors such as situational constraints and managerial interventions of IT (Agarwal et al., 1996), see Section 6.3.

\subsection{Factors identified from Phase 1}

120 of 185 trainees (65\%) and all eight trainers responded. Several different methods of training were used (traditional classroom, classroom assisted video with help from the trainer, workshops using computers, 
individualized booth video training). $76 \%$ of the trainees perceived the technology to be easy to use and the courses to be useful. $66 \%$ preferred the IT-BT aspects of the training, and they had a positive attitude towards the training experience. However, for the majority of the trainees $(68 \%)$ there was not enough time to ask the trainer all of their the questions, and insufficient IT-practice time. They found the manuals complex; some of the trainers lacked appropriate teaching skills. All 8 trainers had a favourable opinion of the training and, contrary to the trainees, perceived that the time spent on explanations and practice during the training were both adequate. The trainers' interview showed that they adjusted their teaching style to match the different abilities of the trainees.

Observations of the trainees during the hands-on session showed that the trainer and trainees interacted through question and answer episodes; the trainees also interacted and assisted one another. Post-questionnaire results showed that they felt that the course contributed to their ability to use IT and they enjoyed this type of learning. Management also perceived this training positively and felt that the organization needed this training. Factors resulting from the first phase included both personal factors (e.g., attitude, perceived behavioural control), and institutional factors (e.g., management's perspective, the trainers' attitude toward the training, organization of the training and delivery mode). The results showed that some institutional factors negatively affected the training experience, such as a lack of resource provisions, insufficient practice time during the training sessions, and the trainers' lack of appropriate teaching skills.

\subsection{Conceptual model for evaluating IT-Based training}

The literature review and empirical evidence from Phase 1 show that the following factors need to be considered when measuring the effectiveness of IT-BT. These include personal factors, such as the attitudes of the trainees towards IT and training, their perceived locus of control of IT and training, and the influence of attitude on their change in practice and actual use of IT in the work-place. The institutional factors include the management's perspective of the training, the trainers' attitudes towards the training, organization of the training, the delivery mode and the training experience. The outcomes in the model include the trainees' changed attitude towards IT and training, their acquisition of new knowledge and skills and their improved work practices. The conceptual model was adapted from Schifter and Ajzen (1985) for use with IT (Figure 1). It shows the personal factors such as attitudes and subjective norms and how these relate to perceived behavioural control and performance. The combined model of the training 
process including institutional and personal factors (Figure 2) is based on previous research, theories, and results of Phase 1.

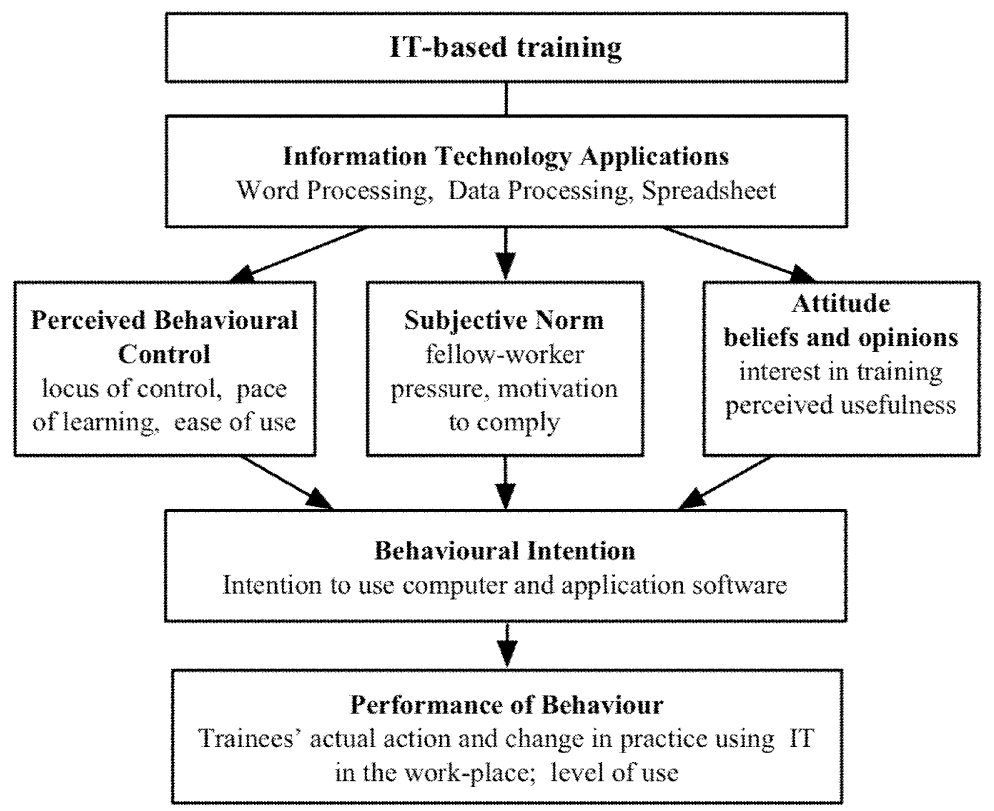

Figure 1: Conceptual Model of the personal factors relating to IT-based training and uptake.

\section{CONCLUSIONS}

Phase 1 results showed that the training did not always lead to the subsequent uptake of IT by all trainees in their work practices. There was often a mismatch between the trainers' and trainees' perceptions of how the training should be organised, and many trainees did not feel confident to use IT after the training. The results of Phase 1 also showed that we needed more detailed information about the trainees' attitudes, and the effects of the institutional factors on their integration of IT in their work. The conceptual model below shows that both personal and institutional factors must be considered when planning IT-BT programmes. This model is now being used in Phases 2 and 3 of our research and can be used by others designing and evaluating IT-BT. Phase 2 involves the same approach as Phase 1 but with a much larger sample (over 500). 
Phase 3 involves further interviews, observation of working practices after the training, and an attitude test to validate the relative importance of the factors in the conceptual model and thereby the model itself.

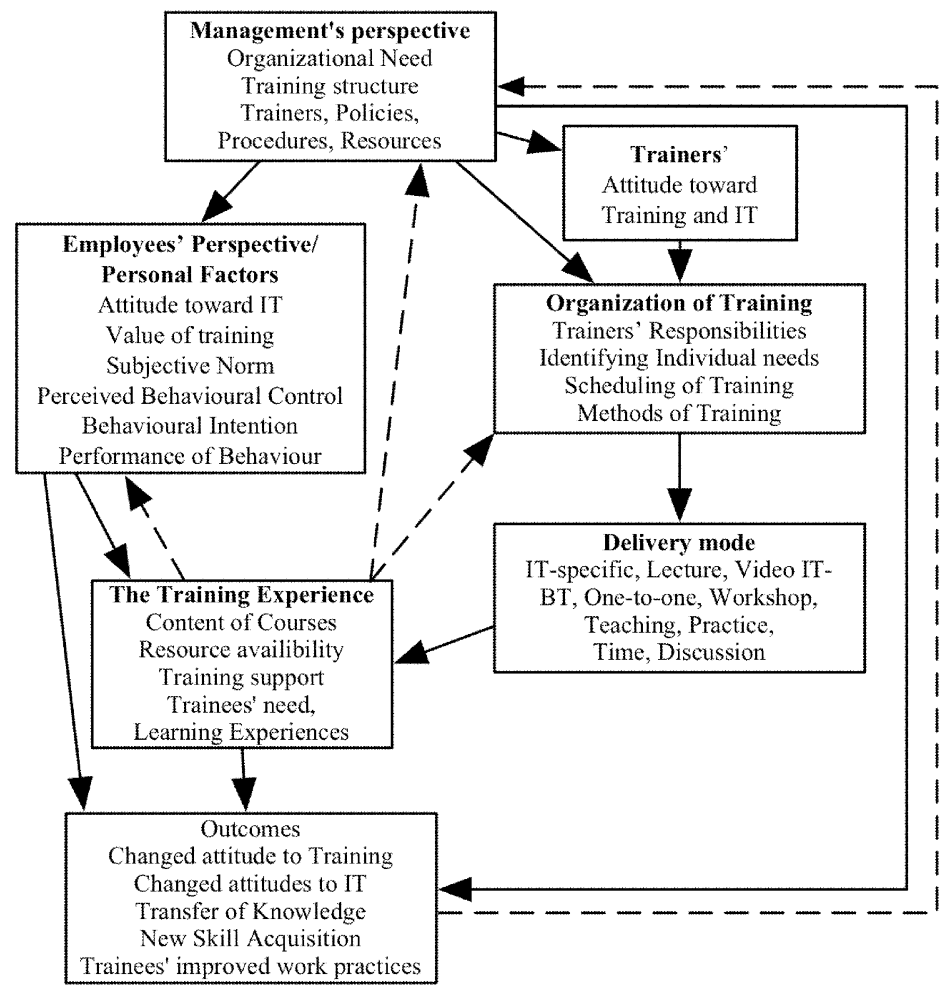

Figure 2. Combined Conceptual Model: Focus on Institutional and Personal Factors.

\section{REFERENCES}

Agarwal, R., Prasad, J., \& Zanino, M. C. (1996). Training experiences and usage intentions: A field study of a graphical user interface. International Journal of Human-Computer Studies, 45, 215-241.

Arnold, J., Cooper, C. L., \& Robertson, I. T. (1995). Work Psychology: Understanding Human Behaviour in the Workplace. (p. 309). London: Pitman Publishing.

Chou, H. W. (2001). Influences of cognitive style and training method on training effectiveness. Computers and Education, 37, 11-25.

Goldstein. I. L., \& Ford, J. K. (2002). Training in Organizations: Needs Assessment, Development and Evaluation, ( $4^{\text {th }}$ ed.). California: Thomas Learning, Inc. 
Harrison, D. A., Mykytyn, P. P., \& Riemenschneider, C. K. (1997). Executive Decisions about Adoption of Information Technology in Small Business: Theory and Empirical Tests. Information Systems Research, 8(2), 171-195.

Kettanurak, V. N., Ramamurthy, K., \& Haseman, W. D. (2001). User attitude as a mediator of learning performance improvement in an interactive multimedia environment: An empirical investigation of the degree of interactivity and learning styles. International Journal of Human-Computer Studies, 54, 541-583.

Leidner, D. E., \& Jarvenpaa, S. L. (1995). The use of information technology to enhance management school education: A theoretical view. MIS Quarterly, 19(3), 265-291.

Nordenbo, S.V. (1990). How do Computer Novices Perceive Information Technology? A Qualitative Study Based on a New Methodology. Scandinavian Journal of Educational Research, 34(1), 43-73.

Rae, L. (1995). Techniques of Training. ( $3^{\text {rd }}$ ed.). Hampshire: Gower Publishing.

Roberts, P., \& Henderson, R. (2000). Information Technology acceptance in a sample of Government Employees: A Test of the Technology Acceptance Model. Interacting with Computers, 12, 427-443.

Rossett, A., \& Gautier-Downes, J. (1991). A Handbook of Job Aids. California: Pfeiffer.

Salas, E., \& Cannon-Bowers, J. A. (2001). The Science of Training: A Decade of Progress. Annual Review of Psychology, 52(1), 471-499.

Schifter, D. B., \& Ajzen, I. (1985). Intention, perceived control, and weight loss: An application of the Theory of Planned Behavior. Journal of Personality and Social Psychology, 49, 843-851.

Torkzadeh, G., \& Van Dyke, T. P. (2002). Effects of Training on Internet Self-efficacy and Computer User Attitudes. Computers in Human Behaviour, 18(5), 479-604.

Venkatesh, V., \& Speier, C. (2000). Creating an Effective Training Environment for Enhancing Telework. International Journal of Human-Computer Studies, 52, 991-1005.

Wishart, J., \& Blease, D. (1999). Theories underlying perceived changes in teaching and learning after installing a computer network in a secondary school. British Journal of Educational Technology, 30(1), 25-41.

Wynekoop, J. L. (1992). Strategies for Implementation Research: Combining Research Methods. In J. DeGross et al. (Eds.), Proceedings of the $13^{\text {th }}$ Annual International Conference on Information Systems, Dallas, Texas, December, pp. 185-193.

\section{BIBLIOGRAPHY}

Margaret Cox has research interests in the use of ICT in education and their effects on teaching and learning, and motivation; teacher training in the uses of ICT; development and evaluation of computer-based modelling and simulations; the uptake of ICT in education; use of ICT in science education and in Dental undergraduate programmes. Lena Wilkinson is an Adjunct Faculty member at the School of Business and Technology, Webster University. Her research focuses on IT-CBT and organisational and employee attitudes and behaviour towards the uses of ICT for training, professional development and changes in work practices. 